\title{
THE ANAESTHETIC EFFECT OF CLOVE OIL ON COMMON CARP, CYPRINUS CARPIO L.
}

\author{
Grzegorz J. HAJEK*, Bernard KŁYSZEJKO, Robert DZIAMAN \\ Division of Fish Physiology, Agricultural University of Szczecin, Szczecin, Poland
}

\begin{abstract}
Hajek G.J., Kłyszejko B., Dziaman R. 2006. The anaesthetic effect of clove oil on common carp, Cyprinus carpio L. Acta Ichthyol. Piscat. 36 (2): 93-97.
\end{abstract}

Background. Clove oil, containing the active ingredient eugenol, has been reported to be an inexpensive and effective fish anaesthetic. The objective of the presently reported study was to establish the lowest effective concentration of clove oil for the common carp, Cyprinus carpio L., and safe working ranges for the anaesthetic.

Materials and Methods. Carp were exposed to the concentrations of 10, 20, 30, 40, 50, 100, 150, and $200 \mathrm{mg} \cdot \mathrm{L}^{-1}$ of clove oil. The onsets of individual phases of anaesthesia and recovery rates were studied. In experiment 1 the fish were held in the anaesthetic bath until the lack of responses to handling was observed and in experiment 2 - until the fading of ventilation.

Results. Clove oil at the concentrations ranging from 30 to $200 \mathrm{mg} \cdot \mathrm{L}^{-1}$ induced general anaesthesia. The lowest concentration causing general anaesthesia with an average induction time below $3 \mathrm{~min}$ was $40 \mathrm{mg} \cdot \mathrm{L}^{-1}$. Recovery was concentration-independent and lasted for about $4 \mathrm{~min}$ (experiment 1). An increase in the concentration shortened the time of ventilation during anaesthesia and prolonged the recovery (experiment 2 ).

Conclusion. Clove oil is a potent anaesthetic for carp, the safest and most effective at the concentrations of 30-50 $\mathrm{mg} \cdot \mathrm{L}^{-1}$. Therefore those solutions should be used, in the aquaculture practice, when the procedure requires more than 5 min of the exposure to the anaesthetic.

Keywords: clove oil, eugenol, anaesthesia, common carp, Cyprinus carpio, fish

\section{INTRODUCTION}

Anaesthetics play an important role in both fisheries research and aquaculture, being used to facilitate various handling procedures, such as weighing, sorting, collection of spawning material, tagging, or veterinary treatment (Summerfelt and Smith 1990, Kazuń, Siwicki 2001).

Anaesthetics act with various intensity, driving fish into general anaesthesia, resulting in loss of consciousness, inhibition of reflex activity, and reduced skeletal muscle tone (McFarland 1960). Regardless of the agent, the process of anaesthesia in fish, develops in a similar way and runs in a progressive pattern (McFarland 1959). Overdosing an anaesthetic or retaining the fish in an anaesthetic bath for too long leads to the fading of ventilation, hypoxia, and finally - respiratory and cardiac collapse (Tytler and Hawkins 1981). The fading of ventilation is an important warning sign suggesting that the exposure should be terminated (Hajek and Kłyszejko 2004, Dziaman et al. 2005).
The most widely used anaesthetics include MS-222 (tricaine methanesulphonate), benzocaine, etomidate, metomidate, 2-phenoxyethanol, quinaldine, and quinaldine sulphate. Also clove oil has recently been pointed out as a potential fish anaesthetic. Clove oil is derived from the stem, leaves, and buds of the clove tree, Eugenia caryophyllata, and it contains the active ingredient eugenol. It has been reported to be effective on several species of fish (Soto and Burhanuddin 1995, Anderson et al. 1997, Munday and Wilson 1997, Keene et al. 1998, Peake 1998, Iversen et al. 2003, Wagner et al. 2003). Its main advantages lie in its low cost, and its relative safety to both fish and humans (Keene et al. 1998).

There has been only one attempt to study the effects of clove oil on common carp, performed by Velíšek at al. 2005. Those authors investigated acute toxicity (LC) of clove oil using 10-min and 96-h exposure time with a survival as the main criterion. The objective of the presently reported study was to establish the lowest effective con-

\footnotetext{
* Correspondence:Dr Grzegorz Hajek, Zakład Fizjologii Ryb, Akademia Rolnicza w Szczecinie, ul. Kazimierza Królewicza 4, 71-550 Szczecin, Poland, phone: (+4891) 4231061 ext. 254, e-mail: gjh@fish.ar.szczecin.pl
} 
centration (defined by Gilderhus 1990) and safe working ranges based on the criterion of the regularity of ventilation.

\section{MATERIAL AND METHODS}

The experiments were carried out using 169 common carp with average weight of $32.6 \pm 8.2 \mathrm{~g}(\bar{x} \pm s)$. The fish were obtained from a cage culture facility at Gryfino near Szczecin, Poland. Those used in the first experiment 1 were collected in September 2005, while those used in experiment 2 were obtained about one month later. The fish were acclimated for 14 days in a 1000 -L common tank prior to trial, in aerated tap water at $20 \pm 1{ }^{\circ} \mathrm{C}$.

The clove oil ( $80.8 \%$ eugenol) obtained from the "Avicenna-oil" company, Wrocław, Poland, was first dissolved in $95 \%$ ethanol at the ratio of $1: 2$ (clove oil : ethanol) and then diluted by shaking with a small amount of water. The solution was added to the experimental tank $30 \mathrm{~min}$ before the introduction of fish.

The induction and recovery were carried out in two 30$\mathrm{L}$ aquaria with aerated tap water at $20 \pm 1^{\circ} \mathrm{C}$. After the experiments the fish were transferred to a 1000-L tank and observed for 10 days.

The "lowest effective concentration" is the concentration that produces general anaesthesia within $3 \mathrm{~min}$ and allows the recovery within $10 \mathrm{~min}$ (Gilderhus 1990, Weyl et al. 1996).

The term "safe exposure time" denotes the part of exposure when the fish breathe regularly, without signs of oxygen deficiency.

This experimental protocol was approved by the Local Ethical Committee for Experiments on Animals (Agricultural University of Szczecin, Poland)

\section{Experimental protocol}

Experiment 1 (Determining the lowest effective concentration of clove oil). The fish were individually placed in the test aquarium with an anaesthetic solution and held there until the lack of responses to handling. To assess the depth of anaesthesia the fish were taken by hand and removed from the water. If there was a response, the exposure was continued, if there was no reaction, the fish were weighed and transferred to the recovery tank and observed until they regained a full movement activity. The time of induction and recovery was measured (in seconds) and changes in the behaviour noted. The concentrations of 10 , $20,30,40,50,100,150$, and $200 \mathrm{mg} \cdot \mathrm{L}^{-1}$ of clove oil were used.

Experiment 2 (Determining safe exposure time of the to effective concentrations of clove oil). The procedure for this experiment was the same as for the first one, except for the duration of the exposure. The fish were held in the anaesthetic bath until the fading of the ventilation was observed. The exposure was terminated when the intervals between individual respiratory movements extended to $4-5 \mathrm{~s}$. The concentrations of $30,40,50,100,150$, and $200 \mathrm{mg} \cdot \mathrm{L}^{-1}$ of clove oil were used.

To describe the process of anaesthesia we used a modified classification of anaesthesia stages adopted from Schoettger and Julin (1967):
1. Sedation-reduced mobility

2. Partial loss of equilibrium-lateral (side) inclination

3. Total loss of equilibrium - almost horizontal position of the fish on the bottom of the tank; weak body movements; removal from the water evoking agitation

4. General anaesthesia-no body movement except for regular ventilation, no reaction to being caught and removed from the water

5. Medullary collapse-respiratory movement ceases

Statistical analyses were performed using General Linear Model:

$$
Y_{i j k}=\mu+K_{i}+b_{j}\left(x_{j}-m\right)+e_{i j k}
$$

where:

$Y_{i j k} \quad$ response time [s]

$\mu$ overall mean

$K_{i} \quad$ the effect of a particular concentration

$b_{j} \quad$ regression coefficient of fish weight

$x_{j} \quad$ individual fish weight

$m$ mean weight

$e_{i j k} \quad$ random error

The Tukey Test was used to compare the means and Spjotvoll-Stoline test for samples of unequal size.

The data of "recovery" and "general anaesthesia" from the experiment 1 and the data of "fading ventilation", "regular ventilation", "regaining equilibrium", and "recovery" from experiment 2 were transformed logarithmically to restore the normality in the distribution and reduce the variance. The transformed data were analyzed but the original values are presented in Tables 1 and 2 .

\section{RESULTS}

Experiment 1. The clove oil administered at the concentrations ranging from 30 to $200 \mathrm{mg} \cdot \mathrm{L}^{-1}$ resulted in progressive anaesthesia. After the transfer to a tank with clean water all the fish recovered. Anaesthesia symptoms faded in a reverse order. The mean times of the duration of anaesthesia and the recovery symptoms are presented in Table 1.

The clove oil at the concentration of $10 \mathrm{mg} \cdot \mathrm{L}^{-1}$ resulted in sedation only. The concentration of $20 \mathrm{mg} \cdot \mathrm{L}^{-1}$ caused the equilibrium disturbances in all fish and general anaesthesia of one fish within $10 \mathrm{~min}$. The increase in the concentration resulted in the shortening of induction. The lowest concentration of clove oil resulting in general anaesthesia in less than 3 min was the concentration of 40 $\mathrm{mg} \cdot \mathrm{L}^{-1}$.

In the recovery process, the longest period of regaining equilibrium was observed at the highest concentration, but full recovery did not depend on the concentration and lasted for about $4 \mathrm{~min}$.

Experiment 2. In this experiment the exposure continued until fading of ventilation was observed. The transfer of the fish to the second aquarium resulted in a recovery which began with regaining regular ventilation. 
Timing [s] of anaesthesia- and recovery phases in carp exposed to various clove oil concentrations; mean values \pm standard error of the mean (in parentheses)

\begin{tabular}{lcccccccc}
\hline \multirow{2}{*}{ Stage } & \multicolumn{7}{c}{ Concentration $\left[\mathrm{mg} \cdot \mathrm{L}^{-1}\right](n=12)$} \\
\cline { 2 - 8 } & 10 & 20 & 30 & 40 & 50 & 100 & 150 & 200 \\
\hline Sedation & $35^{\mathrm{aABCDEF}}$ & $26^{\mathrm{A}}$ & $28^{\mathrm{a}}$ & $26^{\mathrm{B}}$ & $22^{\mathrm{C}}$ & $21^{\mathrm{D}}$ & $23^{\mathrm{E}}$ & $24^{\mathrm{F}}$ \\
& $(3)$ & $(2)$ & $(1)$ & $(1)$ & $(1)$ & $(1)$ & $(1)$ & $(1)$ \\
$\begin{array}{l}\text { Partial loss } \\
\text { of }\end{array}$ & - & $168^{\mathrm{ABCDEF}}$ & $59^{\mathrm{AGHI}}$ & $53^{\mathrm{aB}}$ & $38^{\mathrm{C}}$ & $32^{\mathrm{DG}}$ & $32^{\mathrm{EH}}$ & $31^{\mathrm{aFI}}$ \\
equilibrium & - & $(12)$ & $(4)$ & $(4)$ & $(1)$ & $(1)$ & $(2)$ & $(2)$ \\
$\begin{array}{l}\text { Total loss } \\
\text { of }\end{array}$ & - & - & $125^{\mathrm{ABCDE}}$ & $94^{\mathrm{AFGHI}}$ & $56^{\mathrm{BF}}$ & $41^{\mathrm{CG}}$ & $40^{\mathrm{DH}}$ & $39^{\mathrm{EI}}$ \\
equilibrium & - & - & $(24)$ & $(7)$ & $(3)$ & $(2)$ & $(2)$ & $(2)$ \\
$\begin{array}{l}\text { General } \\
\text { anaesthesia }\end{array}$ & - & - & $226^{\mathrm{ABCDE}}$ & $140^{\mathrm{AFGHI}}$ & $74^{\mathrm{BF}}$ & $51^{\mathrm{CG}}$ & $47^{\mathrm{DH}}$ & $44^{\mathrm{EI}}$ \\
$\begin{array}{l}\text { Regaining } \\
\text { equilibrium }\end{array}$ & - & - & $(29)$ & $(8)$ & $(6)$ & $(2)$ & $(2)$ & $(2)$ \\
Recovery & - & - & $99^{\mathrm{A}}$ & $71^{\mathrm{aB}}$ & $102^{\mathrm{C}}$ & $112^{\mathrm{D}}$ & $136^{\mathrm{aE}}$ & $227^{\mathrm{ABCDE}}$ \\
& - & - & $(15)$ & $(12)$ & $(15)$ & $(10)$ & $(10)$ & $(17)$ \\
& - & - & 266 & 226 & 239 & 230 & 230 & 299 \\
\end{tabular}

Mean values having the same superscript (capital) letter in the same row are significantly different at $P \leq 0.01$; mean values having the same superscript (lower-case) letter in the same row are significantly different at $P \leq 0.05$

The mean times of the duration of anaesthesia and recovery symptoms are presented in Table 2 .

The induction time decreased along with the increase of the concentration from $2 \mathrm{~min} 28 \mathrm{~s}$ at the concentration of $30 \mathrm{mg} \cdot \mathrm{L}^{-1}$ to $53 \mathrm{~s}$ at the concentration of $200 \mathrm{mg} \cdot \mathrm{L}^{-1}$. Clove oil at all solutions resulted in the fading of ventilation. The longest safe exposure time (almost $15 \mathrm{~min}$ ) was associated with the solutions of 30 and $40 \mathrm{mg} \cdot \mathrm{L}^{-1}$. An increase in the concentration shortened the time of ventilation during anaesthesia.

All the fish recovered from anaesthesia. The significant differences in the recovery times were independent of the anaesthetic solution. No mortalities were recorded within 10 days post experimental.

\section{DISCUSSION}

The presently reported results confirm the anaesthetic properties of clove oil for common carp. In experiment 1 , the lowest effective concentration causing general anaesthesia with average induction time below 3 min was 40 $\mathrm{mg} \cdot \mathrm{L}^{-1}$. The induction at the solution of $30 \mathrm{mg} \cdot \mathrm{L}^{-1}$, exceeded the time limit of $3 \mathrm{~min}$. In experiment 2 , the induction time at both concentrations was similar and did not exceed $3 \mathrm{~min}$. We do not know why the carp reached the general anaesthesia faster in experiment 2 at $30 \mathrm{mg} \cdot \mathrm{L}^{-1}$. Perhaps it was affected by the fact, that the fish were purchased one month later. We can conclude, that according to our criterion of effectiveness, the concentration of 30 $\mathrm{mg} \cdot \mathrm{L}^{-1}$ of clove oil is a threshold concentration for carp. Also, the experiments conducted on carp (Velíšek et al. 2005b); rainbow trout, Oncorhynchus mykiss (cf. Keene et al. 1998, Prince and Powell 2000, Velíšek et al. 2005a); perch, Perca fluviatilis; and tench, Tinca tinca (cf. Hamáčková et al. 2001, 2004) indicate that the concentration of $30 \mathrm{mg} \cdot \mathrm{L}^{-1}$ of clove oil is not strong enough to induce anaesthesia in less than $3 \mathrm{~min}$. However, the solution of $20 \mathrm{mg} \cdot \mathrm{L}^{-1}$ was effective in that manner on sockeye salmon, Oncorhynchus nerka (cf. Woody et al. 2002) and the solution of $25 \mathrm{mg} \cdot \mathrm{L}^{-1}$ on juvenile longarm mullet, Valamugil cunnesius and silver moony, Monodactylus argenteus (cf. Durville and Collet 2001).

In our experiments the exposure time was not predefined but it was individually adjusted for the reaction of each fish, depending on the anaesthesia level. We observed that if the exposure was prolonged until the fish become anaesthetized, the recovery was concentration-independent and lasted for about $4 \mathrm{~min}$. Similar observations were made by Inoue et al. (2003) on juveniles of matrinxã, Brycon cephalus. The recovery in the experiment with a prolonged exposure was longer at all concentrations, but with the solutions of 30 and $40 \mathrm{mg} \cdot \mathrm{L}^{-1}$ it was still below 10 $\min$.

The results of experiment 2 showed that lower effective concentrations $\left(30-50 \mathrm{mg} \cdot \mathrm{L}^{-1}\right)$ translated into longer duration of general anaesthesia with the ventilation maintained. Therefore, in the aquaculture practice, those solu- 
Timing [s] of anaesthesia- and recovery phases in carp exposed to various clove oil concentrations until the fading of ventilation; mean values \pm standard error of the mean (in parentheses)

\begin{tabular}{|c|c|c|c|c|c|c|}
\hline \multirow{2}{*}{ Stage } & \multicolumn{6}{|c|}{ Concentration $\left[\mathrm{mg} \cdot \mathrm{L}^{-1}\right](n=12)$} \\
\hline & 30 & 40 & 50 & 100 & 150 & 200 \\
\hline Sedation & $\begin{array}{l}26 \\
(2)\end{array}$ & $\begin{array}{l}26 \\
(3)\end{array}$ & $\begin{array}{l}27 \\
(2)\end{array}$ & $\begin{array}{l}24 \\
(3)\end{array}$ & $\begin{array}{l}23 \\
(2)\end{array}$ & $\begin{array}{l}20 \\
(2)\end{array}$ \\
\hline $\begin{array}{l}\text { Partial loss of } \\
\text { equilibrium }\end{array}$ & $\begin{array}{l}42^{\mathrm{A}} \\
(3)\end{array}$ & $\begin{array}{c}46^{\mathrm{aB}} \\
(2)\end{array}$ & $\begin{array}{c}50^{\mathrm{CD}} \\
(2)\end{array}$ & $\begin{array}{c}46^{\mathrm{bE}} \\
(4)\end{array}$ & $\begin{array}{c}34^{\mathrm{abC}} \\
(2)\end{array}$ & $\begin{array}{c}28 \mathrm{ABDE} \\
(2)\end{array}$ \\
\hline $\begin{array}{l}\text { Total loss of } \\
\text { equilibrium }\end{array}$ & $\begin{array}{c}82^{\mathrm{AB}} \\
(8)\end{array}$ & $\begin{array}{l}95^{C D} \\
(8)\end{array}$ & $\begin{array}{c}83^{\mathrm{EF}} \\
(6)\end{array}$ & $\begin{array}{l}68^{\mathrm{a}} \\
(5)\end{array}$ & $\begin{array}{c}47^{\mathrm{ACE}} \\
(3)\end{array}$ & $\begin{array}{c}41 \mathrm{aBDF} \\
\text { (3) }\end{array}$ \\
\hline $\begin{array}{l}\text { General } \\
\text { anaesthesia }\end{array}$ & $\begin{array}{c}148^{\mathrm{ABC}} \\
(16)\end{array}$ & $\begin{array}{c}135^{\mathrm{aDE}} \\
(10)\end{array}$ & $\begin{array}{c}133^{\mathrm{FG}} \\
(6)\end{array}$ & $\begin{array}{c}98^{\mathrm{abAH}} \\
(5)\end{array}$ & $\begin{array}{c}60^{\mathrm{bBDF}} \\
(2)\end{array}$ & $\begin{array}{c}53 \mathrm{CEGH} \\
\text { (3) }\end{array}$ \\
\hline $\begin{array}{l}\text { Ventilation } \\
\text { fading }\end{array}$ & $\begin{array}{c}770^{\mathrm{a} A B C} \\
(46)\end{array}$ & $\begin{array}{c}883^{\mathrm{bdDEF}} \\
(161)\end{array}$ & $\begin{array}{c}510^{\mathrm{abGHI}} \\
(31)\end{array}$ & $\begin{array}{c}277 \mathrm{cdADG} \\
(24)\end{array}$ & $\begin{array}{c}132^{\mathrm{BEH}} \\
(10)\end{array}$ & $\begin{array}{l}90^{\mathrm{cCFI}} \\
(7)\end{array}$ \\
\hline $\begin{array}{l}\text { Regular } \\
\text { ventilation }\end{array}$ & $\begin{array}{c}300 \\
(129)\end{array}$ & $\begin{array}{l}92 \mathrm{AB} \\
(38)\end{array}$ & $\begin{array}{l}176 \\
(47)\end{array}$ & $\begin{array}{c}434 \\
(144)\end{array}$ & $\begin{array}{l}362^{\mathrm{A}} \\
(61)\end{array}$ & $\begin{array}{l}511^{\mathrm{B}} \\
(113)\end{array}$ \\
\hline $\begin{array}{l}\text { Regaining } \\
\text { equilibrium }\end{array}$ & $\begin{array}{c}474 \\
(149)\end{array}$ & $\begin{array}{c}335^{\mathrm{aA}} \\
(51)\end{array}$ & $\begin{array}{c}432762^{\mathrm{a}} \\
(75)\end{array}$ & $\begin{array}{c}586 \\
(153)\end{array}$ & $\begin{array}{l}772^{\mathrm{A}} \\
(85)\end{array}$ & (135) \\
\hline Recovery & $\begin{array}{c}535^{\mathrm{AB}} \\
(152)\end{array}$ & $\begin{array}{c}433^{\mathrm{CD}} \\
(65)\end{array}$ & $\begin{array}{l}524 \\
(76)\end{array}$ & $\begin{array}{l}917^{\mathrm{AC}} \\
(157)\end{array}$ & $\begin{array}{l}718 \\
(87)\end{array}$ & $\begin{array}{c}907^{\mathrm{BD}} \\
(137)\end{array}$ \\
\hline
\end{tabular}

Mean values having the same superscript (capital) letter in the same row are significantly different at $P \leq 0.01$; mean values having the same superscript (lower-case) letter in the same row are significantly different at $P \leq 0.05$

tions should be used when application requires more than $5 \mathrm{~min}$ of the exposure to the anaesthetic.

\section{CONCLUSION}

Concentrations of $30-50 \mathrm{mg} \cdot \mathrm{L}^{-1}$ of clove oil are the safest and the most effective ones when applied to carp, and the solution of $40 \mathrm{mg} \cdot \mathrm{L}^{-1}$ is the lowest concentration that induces anaesthesia in less than $3 \mathrm{~min}$. If the exposure is prolonged until the fish become anaesthetized, the recovery is concentration-independent and lasts for about $4 \mathrm{~min}$

\section{REFERENCES}

Anderson W.G., McKinley R.S., Colavecchia M. 1997. The use of clove oil as an anaesthetic for rainbow trout and its effects on swimming performance. North American Journal of Fisheries Management 17: 301-307.

Durville P., Collet A. 2001. Clove oil used as an anesthetic with juvenile tropical marine fish. SPC Live Reef Fish Information Bulletin (9): 17-19.

Dziaman R., Kłyszejko B., Hajek G. 2005. The effects of MS-222 on the cardiac and respiratory function and behaviour of common carp, Cyprinus carpio L., during general anaesthesia. Acta Ichthyologica et Piscatoria 35: $125-131$.
Gilderhus P.A. 1990. Benzocaine as a fish anesthetic: Efficacy and safety for spawning-phase salmon. The Progressive Fish-Culturist 52: 189-191.

Hajek G.J., Kłyszejko B. 2004. The effects of Propiscin (etomidate) on the behaviour, heart rate, and ventilation of common carp, Cyprinus carpio L. Acta Ichthyologica et Piscatoria 34: 129-143.

Hamáčková J., Lepičová A., Kozák P., Stupka Z., Kouřil J., Lepič P. 2004. The efficacy of various anaesthetics in tench (Tinca tinca L.) related to water temperature. Veterinary Medicine 49: 467-472.

Hamáčková J., Sedova M.A., Pjanova S.V., Lepičová A. 2001. The effect 2-phenoxyethanol, clove oil and Propiscin anaesthetics on perch (Perca fluviatilis) in relation to water temperature. Czech Journal of Animal Science 46: 469-473.

Inoue L.A.K.A., Santos-Neto N.C., Moraes G. 2003. Clove oil as anaesthetic for juveniles of matrinxã Brycon cephalus (Günther, 1869). Ciência Rural 33: 943-947.

Iversen M., Finstad B., McKinley R.S., Eliassen R.A. 2003. The efficacy of metomidate, clove oil, Aqui-STM and Benzoak ${ }^{\circledR}$ as anaesthetics in Atlantic salmon (Salmo salar L.) smolts, and their potential stress-reducing capacity. Aquaculture 221: 549-566. 
Kazuń K., Siwicki A.K. 2001. Propiscin-a safe new anaesthetic for fish. Archives of Polish Fisheries 9: 183-190.

Keene J.L., Noakes D.L.G., Moccia R.D., Soto C.G. 1998. The efficacy of clove oil as an anaesthetic for rainbow trout, Oncorhynchus mykiss (Walbaum). Aquaculture Research 29: 89-101.

McFarland W.W. 1959. A study of the effects of anaesthetics on the behaviour and physiology of fishes. Publications of the Institute of Marine Science (Texas) 6: 23-55.

McFarland W.N. 1960. The use of anesthetics for the handling and the transport of fishes. California Fish and Game 46: 407-431.

Munday P.L., Wilson S.K. 1997. Comparative efficacy of clove oil and other chemicals in anaesthetization of Pomacentrus amboinensis, a coral reef fish. Journal of Fish Biology 51: 931-938.

Peake S. 1998. Sodium bicarbonate and clove oil as potential anaesthetics for nonsalmonid fishes. North American Journal of Fisheries Management 18: 919-924.

Prince A., Powell C. 2000. Clove oil as an anaesthetic for invasive field procedures on adult rainbow trout. North American Journal of Fisheries Management 20: 1029-1032.

Schoettger R.A., Julin A.M. 1967. Efficacy of MS-222 as an anesthetic on four salmonids. United States Fish and Wildlife Service Investigations in Fish Control 13: $1-15$.

Soto C.G., Burhanuddin S. 1995. Clove oil as a fish anaesthetic for measuring length and weight of rabbitfish (Siganus lineatus ). Aquaculture 136: 149-152.
Summerfelt R.C., Smith L.S. 1990. Anesthesia, surgery, and related techniques. Pp. 213-272. In: Schreck C.B., Moyle P.B. (eds.) Methods for fish biology. American Fisheries Society, Bethesda, MD, USA.

Tytler P., Hawkins A.D. 1981. Vivisection, anaesthetics and minor surgery. Pp: 247-278. In: Hawkins A.D. (ed.) Aquarium systems. Academic Press, New York, NY, USA.

Velíšek J., Svobodová Z., Piačková V. 2005a. Effects of clove oil anaesthesia on rainbow trout (Oncorhynchus mykiss). Acta Veterinaria Brno 74: 139-146.

Velíšsek J., Svobodová Z., Piačková V., Groch L., Nepejchalová L. 2005b. Effects of clove oil anaesthesia on common carp (Cyprinus carpio L.). Veterinary Medicine 50 (6): 269-275.

Wagner G.N., Singer T.D., McKinley S.R. 2003. The ability of clove oil and MS-222 to minimize handling stress in rainbow trout (Oncorhynchus mykiss Walbaum). Aquaculture Research 34: 1139-1146.

Weyl O., Kaiser H., Hecht T. 1996. On the efficacy and mode of action of 2-phenoxyethanol as an anaesthetic for goldfish, Carassius auratus (L.) at different temperatures and concentrations. Aquaculture Research 27: 757-764.

Woody C.A., Nelson J., Ramstad K. 2002. Clove oil as an anaesthetic for adult sockeye salmon: Field trails. Journal of Fish Biology 60: 340-347.

Received: 24 March 2006

Accepted: 19 September 2006

Published electronically: 18 November 2006 